\title{
The Study of Extraction and Design Applications of Shaanxi Folk Culture Genes
}

\author{
W.J. Mu, L.L. Chen, S. Deng, L. Li \\ College of Mechanical and Electrical Engineering \\ Northwestern Polytechnical University \\ China
}

\begin{abstract}
In order to inherit and develop the Shaanxi folk culture effectively, to make product designs more diverse and efficient, the introduction of the design principles of genetic engineering process to extract the distinctive culture genes of Shaanxi folk culture, especially on the basis of typical features of folk art and folk culture analysis. Then find a way to explore the application of modern products of Shaanxi folk with examples.
\end{abstract}

Keywords-folk culture; design genes; modern product design

\section{INTRODUCTION}

Shaanxi folk culture is very valuable intangible cultural heritage, because it records the change and development of Shaanxi documented human spirit from different aspects. [1] However, with fewer inheritors of traditional folk culture of Shaanxi, and the traditional folk culture of Shaanxi lack of appropriate new carrier, it cannot close to modern life, which makes the traditional Shaanxi folk cultural heritage has been seriously hampered. To make excellent Shaanxi folk culture heritage continue to develop and collision outstanding design results, the new technologies and new methods combining with industrial design means a lot to our study.

\section{A. Shaanxi Folk Culture_Derived from "Xing"}

Because of its millennium cultural heritage, Shaanxi promotes the reputation of the village of folk arts and crafts. Especially the traditional crafts like the facebook of Huo Ma Shao, paper cutting and clay of Fengxiang. Those traditional crafts have apparent geographical and cultural characteristics of Sanqin land. Those crafts with a strong value of art are very beautiful, and its modeling is extreme exaggerating.

The facebook of Ma Shao developed from the facebook of She Huo of Chinese folk. It is a kind of painting on the Ma Shao. The characters of Ma Shao are form Chinese myth (many of them from Feng Shen Yan Yi, then combined with Qin Qiang Facebook) Artists design the depiction of characters through the facial appearance and color. Ma Shao facebook collect many traditional patterns, including Yun Shui pattern, Ya Sheng Qian, bat pattern, San Zu Jin Chan, fire pattern and so on. Those traditional patterns are highly extraction and abstract of nature.

Feng Xiang painting clay is from soldiers who can make painting clay in Feng Xiang in Qin dynasty. They are both soldiers and farmers at that time. So the Feng Xiang painting clay still keeps the idyllic style. [2] It combines with the style of Nian Hua, paper cutting, ancient stone inscription and embroidery. It earns people's love because of its beautiful color

\author{
Y.L. Jiang \\ College of Mechanical and Electrical Engineering \\ Xian Polytechnic University \\ China
}

and attractive modeling. The main patterns include the toys and folk custom like Zuo $\mathrm{Hu}$, Wu Du, Gua Hu, Wo Niu Shi Er Shngxiao, Ji Hu, Luo Han and so on.

Paper cutting is dated from the "paper cutting of Lou" in Shang dynasty, namely cutting on the leather, metal and jade. With development of papermaking, this skill enjoys wider spread. People can make it easily, so it is booming fast and the art form increasing gradually.[3] Shaanxi paper cutting skill has a lot of forms, including Kang Wei flower, Men Hua, Gua Lian, Chuang Yao Ding flower, Zhen flower, Zhuo Qun flower, Xie flower, wedding double $\mathrm{Xi}$ flower, and ornament on the clothes and so on.

Shaanxi folk cultures realize the Cultural Heritage of millennium Shaanxi culture through lots of artistic expressions. It is the result of combining the collective and individual consciousness. It comes from life and nature, and form special characteristics of Shaanxi Cultural.

\section{B. Shaanxi Folk Culture_Extension of "Yi"}

Shaanxi folk culture's traditional craft is a carrier of customs and beliefs of the Sanqin people. And it has a certain value, spiritual and aesthetic value. The models of Shaanxi folk art, on some of the patterns, are actually no longer just the traditional sense of the natural world. It gives a symbolic meaning according to their characteristics. For example, bats representing fortune, cock representing happiness, pine and crane representing longevity, pomegranate containing more children, bald bird symbolizes life together, mandarin duck and swallow symbolize forever love, peony symbolizes wealth and good fortune, dragon and phoenix on behalf of luck and so on. Those things are symbol of longing for the good fortune of living.

Through the use of symbolic symbols form and use a combination of natural phenomena characteristic of creative expression homophonic. However, as time changes and transfer of modern life, folk cultural needs a new heritage carrier.

By the combination of modern product design and Shaanxi Folk Culture, it is a new way of heritage the modern culture. This not only makes the Shaanxi folk culture to give new life, but also develop Shaanxi folk culture to keep up with the time.

\section{Shaanxi Folk Culture_Inheritance of "Shen"}

The Shaanxi folk traditional patterns and extracted color introduced into areas of product to design products in combination with the traditional patterns and color elements. To design products as well as the design of genes extracted 
secondary processing. In the process of design should break the inherent design of conventional models (to combine Shaanxi folk culture gene mechanically and transplanted directly into the product), and seek the entry point of modern design. Inheritance and development of Shaanxi Folk Culture and produce design culture with modern style folk culture can give Shaanxi folk culture the spirit and meaning of a new era.

\section{INTERPRETATION OF GENETIC ENGINEERING DESIGN}

Gene is the smallest unit of genetic material, and is the performance of the material basis of genetic traits. The essential characteristics of the design process from the starting construct decided to design gene results, and the product design process just as similar to the process of life. Designer could apply the genetic engineering methods to operate design elements gene, by recombinant gene design elements to achieve the design results various, as the same time, use the scientific method to optimize the design results.

\section{A. Understanding the Mechanism}

Recombinant DNA technique is regarded as genetic recombination. It is under controlled conditions by different DNA strand cut, spliced, and the DNA fragments recombine exchange, forming a new DNA molecule to promote growth process of evolution. Recombinant include three levels of meaning: (1)Filter extraction; (2) Repair Links; (3) Integration and optimization. Through these three levels of operating procedures, so that the organism stable inherit and express a new trait in accordance with the wishes of the people.[4]

\section{B. Design Adaptive Gene}

Design gene adaptability is a new product, which designed to measure the recombinant gene after the satisfaction of the needs. Designers replace lower adaptive cultural genes off, replaced by a high adaptability of cultural genes.

Based on the value of the target product design diversity, recombinant organic integration of its unique way of Shaanxi

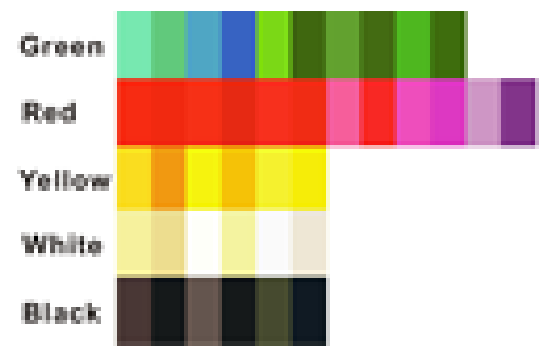

FIGURE I. FIVE COLOR GENE EXTRACTION PATTERNS IN SHAANXI FOLK

Folk culture will enrich the gene extracted and integrated into the product design, by screening the formation of rich folk culture meaning of modern design. At the same time, changing social environment driven recombinant Shaanxi folk cultural elements continued reconstruction, constantly absorbing, prompting modern product design and produce dynamic association of Shaanxi Folk Culture. Finally, it forms a dynamic and sustainable design process, "Extraction-Integration--Abstraction--Adaptation--Re-integration--Reabstraction--Re-adaptation".

\section{EXTRACTION OF GENES SHAANXI FOLK CULTURE}

Through the process of "Extraction--Abstraction-Integration", extracted Shaanxi most unique traditional colors, traditional patterns, and into a corresponding modern elements.

According to the extracted color gene "green, red, yellow, white, black," five color gene encodes, then we recorded them as $F(i), G(j), H(m), I(n), J(q)$, (among them $i, j, m, n, q$ on behalf of 1-12). Color extracted by the Shaanxi Shehuo Ma Shao facebook, Shaanxi Fengxiang clay sculpture and other classified integrates physical extraction.[5]

We extracted genes of Shaanxi folk patterns, then initially classified into the following five categories ornamentation gene. We recorded them as $\mathrm{M}(\mathrm{a}), \mathrm{N}(\mathrm{b}), \mathrm{X}(\mathrm{c}), \mathrm{Y}(\mathrm{d}), \mathrm{Z}(\mathrm{e})$, (among them $\mathrm{a}, \mathrm{b}, \mathrm{c}, \mathrm{d}$, e taken a positive integer).

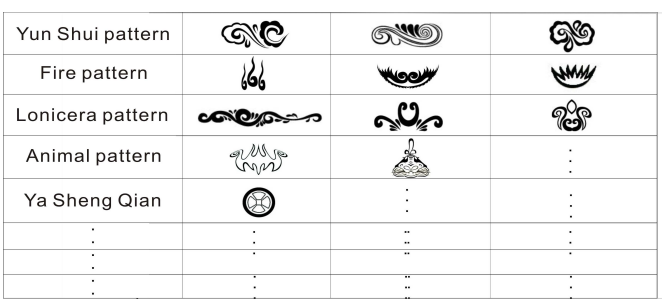

FIGURE II. EXTRACTION GENES OF SHAANXI FOLK PATTERNS

\section{The Product Design Process Design Based on SHAANXI FOLK CULTURE GENE}

After analysis to extract color and patterns of gene Shaanxi folk culture, and establishing clear framework.(according to picture 3) These genes effectively organized and stored in the gene pool, the genetic recombination, will have shown with many of the portfolio effect through multi-level.

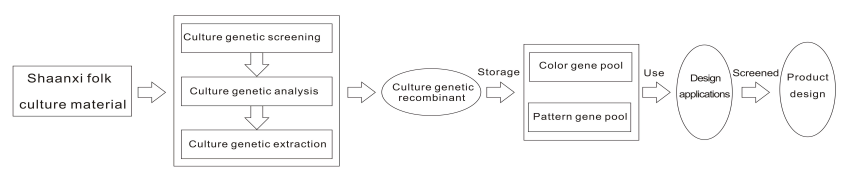

\section{FIGURE III. APPLICATION FLOW CHART OF SHAANXI FOLK CULTURE GENE}

By research of Shaanxi folk culture and genetic, we determine that Shaanxi folk culture gene pool includes gene pool of color and pattern; products gene pool includes vector gene library(various types of modern products)(according to picture 4).

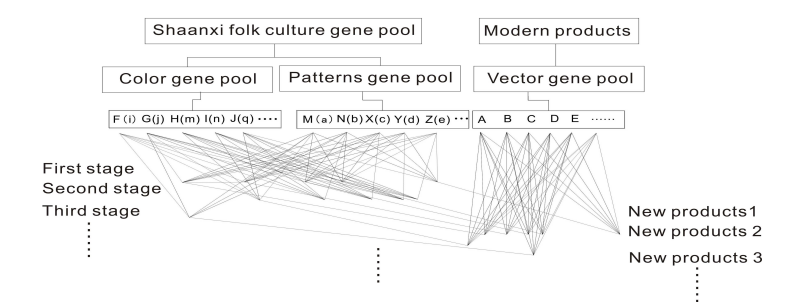

FIGURE IV. RECOMBINANT ARCHITECTURE OF SHAANXI FOLK CULTURE OF GENE POOL

Work principle: After every permutations and combinations of the same level of the gene, it can produce many different forms of composition. We selected gene patterns $\mathrm{F}(\mathrm{i})$ and $\mathrm{M}(\mathrm{a})$, 
$\mathrm{N}(\mathrm{b}), \mathrm{X}(\mathrm{c}), \mathrm{Y}(\mathrm{d}), \mathrm{Z}(\mathrm{e})$ extracted gene from color gene libraries under the same level of free combination computer. While permutated multi-color multi-decoration freely, we combine with the recombinant vector obtained in every product gene library by combining recombinant product. After that the new products will be screened. Finally, the design needs to meet certain conditions to optimize the design of the product, in order to achieve the ultimate goal of the design, and the process is called integration and optimization.

\section{Design Method of Modern Product of FolK CUlTuRE}

\section{A. Change in Dimension}

Dimension refers to the angle of the target object analysis used in our analysis, commonly used in mathematics, physics. The dimensions of the introduction of designs, mainly we extract three-dimensional gene conversion elements. The new one will replace the original carrier, so Shaanxi folk culture can burst of new life.

\section{B. Material Substitution}

The traditional material used clay, wood, plant stalks, leather, paper and cloth. Modern product design can use paper, metal, glass, wood, metal, plastic, leather, etc. Due to large numbers of new materials and large quantities of good attributes processing, it will be better adapt to the trend of modern design. To make the product more suitable for modern life, we need to design products in time for the material indepth exploration of innovative practice. It can meet the functional basis, but also to meet the spiritual pursuit of modern people.

\section{Simplification and Stitching of Folk Culture Symbols}

The extracted gene Shaanxi folk culture elements to break up the reorganization, deformation stitching can make traditional patterns become more diverse. We analyzed the Mashao facebook as follows: Moire is the circle motifs, waterlines is the swirl pattern. Cloud water pattern is a combination of an arc or a wavy pattern even decorative pattern made by the combination of convex and concave shape, like the cloud water flow. "Yuntou", painted clouds curled pattern diagram, while "Tao yun guai zi" painted clouds connection tortuous pattern diagram. The moiré and waterlines can be obtained with a certain modern and diverse transformation, in line with the modern aesthetic ideas of graphics.

\section{Reproduction of Rhyme}

Beijing 2008 Olympic Torch design was inspired by "origin of symbiosis, harmony and communion" and "clouds" pattern. The moiré is the theme pattern, using silver with red, producing eye-catching visual effects. The torch split properly, with cloud patterns and three-dimensional embossed design process, so that the whole torch elegant gorgeous, heavy connotation. The torch is made use of the light-weight aluminum alloy material, the cone-shaped curve in terms of a molding process technology and aluminum corrosion and stain techniques. The production of materials of the torch is recyclable materials. (According to Fig5) These are all excellent design elements from traditional Chinese culture.

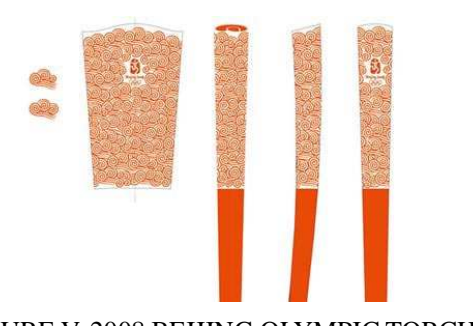

FIGURE V. 2008 BEIJING OLYMPIC TORCH

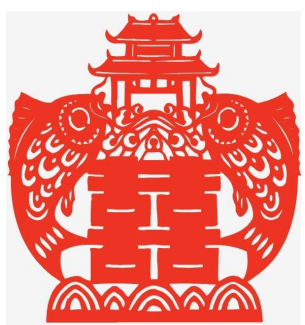

FIGURE VI. SHAANXI FOLK PAPER -CUT -"BIG SPLASH "

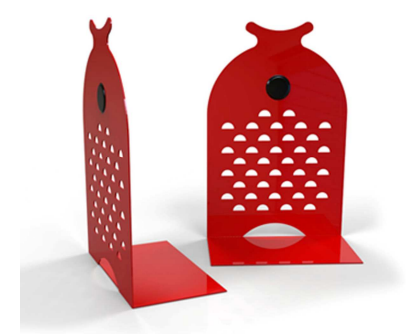

FIGURE VII. "BIG SPLASH” BOOKEND

\section{CASE STUdy OF SHAANXI FOLK CULTURE AND MODERN DESIGN}

By "Collected extraction -combination of abstraction Screening integration", designers can combine the color gene pool, the patterns gene pool with the carrier gene pool. Through a reasonable exaggerated and distorted of extraction patterns, a series of design products with practical and cultural value are achieved.

The figure above is the first type of genetic recombination, which is a single-color extract gene combination of monochrome ornamentation. Fig7 shows the extraction of northern Shaanxi paper-cut element and the image of carp was properly abstract exaggeration to make the new design with cartoon sense of fun, which also expressed ideal life pursuit uplifting. Metal material and the coating process on the traditional crafts express a new visual and tactile excitation. With certain function of easy to carry, book end not only continues the traditional culture propagation, but also adds fun to people's lives.

The second type is extracted gene combinations with single color and multi-ornamentation. Fig8 is postcard series of Shaanxi Top Ten Strange, which use environmentally friendly paper and hollow effect to make the product more approachable with new functionality. Extracting paper-cut shape for the gene patterns and further refines the process: it 
means combination of traditional northern Shaanxi paper cutting techniques and modern product carrier. Finally, the product displays heavy sense and has certain collectible value.

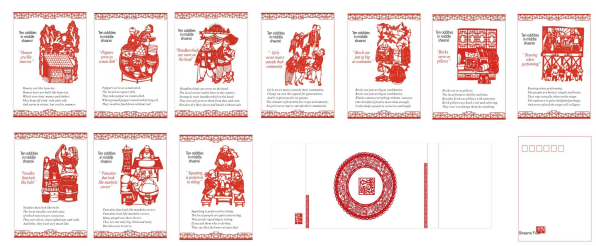

FIGURE VIII. POSTCARD OF THE TOP TEN STRANGE IN SHAANXI
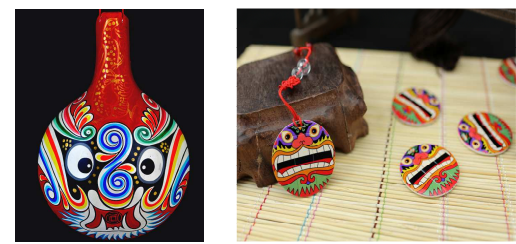

FIGURE IX. U-DISK OF SHAANXI LADLE FACIAL MAKE-UP DESIGN

The third type is extraction of multi-color and multiornamentation. According to more than ten kinds of traditional craft objects among Shaanxi folk culture, Institute of Industrial Design of Northwestern Polytechnical University self-design series of product. For example, Ladle U disk (Fig9) is popular with the majority of young people.[6]

\section{CONCLUSION}

This article combines Shaanxi folk cultural elements and genetic engineering together to propose the construction and use of Shaanxi folk culture gene pool. It proves feasibility and effectiveness of gene pool, enhancing the cultural flavor of the product and adds certain fun to the product. However, Shaanxi folk culture is very profound and extracting genes is not complete yet. What I hope is that we can continue to improve practice in the future.

\section{REFERENCES}

[1] Wang Cong. On the Shaanxi Folk Culture [J] Theoretical Construction 2007

[2] Zhou Shaoping. Study on Fengxiang Folk Clay [J] . Arts and Culture Study 2013

[3] Song Yang. Innovation in Shaanxi paper-cut images of fabric design Reengineering [D] .2012

[4] Xu Yuhui, Wei Ning Genetic Recombination: Urban Design Method Based on Cultural Resource Integration [M] Huazhong Architecture 2012

[5] Zheng Rensi. Study on Fengxiang traditional folk patterns and cultural meaning [D] .2012

[6] Figure9. The patent belongs to Institute of Industrial Design of Northwestern Polytechnical University. 